\title{
Microfinance Performance and Social Capital: A Cross-Country Analysis
}

\author{
Luminita Postelnicu ${ }^{1}$ Niels Hermes ${ }^{1,2}$
}

Received: 11 March 2016/Accepted: 7 September 2016/Published online: 19 September 2016

(c) The Author(s) 2016. This article is published with open access at Springerlink.com

\begin{abstract}
In recent years, the microfinance industry has received a substantial amount of cross-border funding from both public and private sources. This funding reflects the increasing interest in microfinance as part of a more general trend towards socially responsible investments. In order to be able to secure sustained interest from these investors, it is important that the microfinance industry can show evidence of its contribution to reducing poverty at the bottom of the pyramid. For this, it is crucial to understand under what conditions microfinance institutions (MFIs) are able to reduce poverty. This paper contributes to this discussion by investigating the relationship between the extent to which social capital formation is facilitated within different societies and the financial and social performance of MFIs. This focus on social capital formation is important, because in many cases MFIs use group loans with joint liability to incentivize asset-poor borrowers to substitute the lack of physical collateral by their social capital. Hence, the success of a large part of the loan relationship between MFIs and their borrowers depends on the social capital those borrowers can bring into the contract. We carry out a cross-country analysis on a dataset containing 100 countries and identify different social dimensions as proxies for how easy social capital can be developed in different countries. We hypothesize that microfinance is more successful, both in terms of their financial and social
\end{abstract}

Niels Hermes

c.l.m.hermes@rug.nl

1 Solvay Brussels School of Economics and Management (SBS-EM), Université Libre de Bruxelles, Brussels, Belgium

2 Faculty of Economics and Business, University of Groningen, Nettelbosje 2, 9747 AE Groningen, The Netherlands aims, in societies that are more conducive to the development of social capital. Our empirical results support our hypothesis.

Keywords Microfinance - Social capital · Financial performance $\cdot$ Social performance

\section{Introduction}

Microfinance institutions (MFIs) focus on providing financial services, in most cases by offering (very) small loans, to poor households that are excluded from the formal financial system. The practice of microcredit started in the mid-1970s and since then it has grown rapidly. The market for microcredit has been booming, especially since the early 2000s. Although the global financial crisis led to a reduction of the growth of microfinance activities (Wagner and Winkler 2013), microfinance has remained high on the agenda of policy makers as a potentially important instrument to reduce poverty. The main driver of its growth has been the belief that having access to finance is crucial for the poor as this helps them to smooth their consumption, generate business opportunities, and improve their inclusion in the formal economy in the long run (Collins et al. 2009). By facilitating self-employment and entrepreneurship, access to credit would help the poor to lift themselves out of poverty (Morduch 1999; Armendáriz and Labie 2011). For this reason, some have argued that the microfinance industry should be seen as ethically progressive (Hudon and Sandberg 2013). Others have made the claim that microfinance is "...one of the fastest growing corporate social responsibility (CSR) tools in the finance sector" (Pohl and Tolhurst 2010, p. 180). 
In recent years, however, microfinance industry has become subject of increasing criticism. In fact, some even go as far as claiming that the industry is currently facing an ethical crisis (Hudon 2011). This crisis was triggered by a number of events, starting in 2007 with the critical attention the Mexican MFI Compartamos received when it was found out that its financial success was at least partly based on interest rates in excess of $100 \%$ their clients had to pay (Lewis 2008). Also in 2007, an authoritative impact study was published, showing that microcredit does not contribute to improving the living conditions of the poor (Banerjee et al. 2013). This study was followed by several other impact studies showing little evidence that microcredit has a positive impact on poverty reduction. ${ }^{1}$ And finally, in 2010, MFIs in India were accused of using exploitative lending techniques and using forceful loan recovery practices, leading to the suicide of several Indian MFI clients (Biswas 2010; Mader 2013).

Notwithstanding the criticism microfinance has received, the sector still obtains a substantial amount of cross-border funding. ${ }^{2}$ The largest part of this funding is from public sources (e.g., multilateral institutions, governmental donors, etc.), but private funding from commercial banks, pension funds insurance companies, private equity firms, etc. has been growing and has actually grown at a faster rate than that of public funders during recent years (El-Zoghbi et al. 2011). ${ }^{3}$ This growth reflects the increasing interest in microfinance as part of a more general trend towards socially responsible investments (SRI). These investments, combining investors' financial objectives with concerns about environmental, social, and governance issues, have become increasingly popular around the world.

In order to be able to secure sustained interest from these investors, it is important that MFIs can show evidence of their contribution to reducing poverty at the bottom of the pyramid. For this, it is crucial to understand under what conditions MFIs are able to contribute to poverty reduction (i.e., their business model is socially sustainable) and when they can reach this for the longer term (i.e., their business model is financially sustainable). In this respect, MFIs are often characterized as hybrid

\footnotetext{
${ }^{1}$ See Bauchet et al. (2011) for an overview of these impact studies and a summary of their findings.

${ }^{2}$ For example, in 2009 (i.e., in the middle of the global financial crisis and just 2 years after the criticism on microfinance started to emerge) total funding reached US\$21.3 billion, which was $17 \%$ higher than the total cross-border flows for 2008 (El-Zoghbi et al. 2011).

${ }^{3}$ Recent examples of the storng interest of private investors for investing in microfinance are the very successful IPOs of Ujjivan Financial Services and Equitas Holdings, two Indian MFIs. Both IPOs attracted substantial investor interest as they were 41 and 17 times oversubscribed, respectively (Money Control 2016; Juhasz 2016).
}

institutions (Battilana and Dorado 2010; Morduch 1999). The current study can be seen in this light as we contribute to the literature on the determinants of the financial and social performance of MFIs.

From its start in the 1970 s, a large part of the microcredit offered to the poor has been characterized by innovative lending methodologies implemented by MFIs in order to increase the probability of repayment of loans. In many cases, these MFIs use the so-called group loans with joint liability to incentivize asset-poor borrowers to substitute the lack of physical collateral by their social capital. Hence, the success of a large part of the relationship between MFIs and their borrowers depends on the social capital those borrowers can bring into the contract.

To explain the drivers of the financial and social performance of MFIs, research has mostly focused on institution-specific factors, such as the type of loans issued, governance, and the formal type of the institution (see, e.g., Mersland et al. 2011), as well as on macroeconomic factors and the formal institutional context (see Ahlin et al. 2011; Hermes and Meesters 2011). Yet, there is very little evidence with respect to how country-level disparities in terms of social capital availability are related to the MFI performance.

This may be due to the difficulty of quantifying the different facets of social capital. Nahapiet and Ghoshal (1998) summarize these different facets into three categories: structural social capital (the presence or absence of relationships between individuals, the configuration of their networks, the characteristics of interpersonal connections, such as network connectivity, density), relational social capital (the type of relationship developed through past social interactions, like respect, trust, acceptance, friendship, sociability), and cognitive social capital (shared norms and languages, shared narratives).

A few studies have recently engaged in proxying social determinants of MFI performance through measurements such as generalized social trust or various cultural dimensions (see, e.g., Karlan 2007; Burzynska and Berggren 2015; Manos and Tsytrinbaum 2014). However, no study has looked at how MFI performance is predicted by the extent to which social contexts facilitate the formation of social capital. Building on Nahapiet and Ghoshal (1998), we argue that social capital formation is facilitated by social determinants such as trust (i.e., relational social capital) or shared cultural aspects (i.e., cognitive social capital) and hypothesize that social capital-based lending contracts are likely to be more successful in societies where less hurdles are encountered in the process of social capital accumulation.

Research has indicated that copying the social capitalbased lending models to different contexts may not always be successful. For example, Masanjala (2002), based on a 
study of the performance of a Grameen-type MFI in Malawi, questions the replicability of Grameen-type banks in Africa. Walker (2012) comes to a similar conclusion based on a study of a Grameen-type bank in the Comoros. These studies suggest that it may indeed be relevant to look at differences between societies in terms of how social capital formation is facilitated, in order to understand the success/failure of social capital-based lending models. To our knowledge, no research looks at the link between MFI performance and the extent to which social capital formation is facilitated within a society. Our study may shed light on the characteristics of the social contexts in which microfinance can be successful.

This paper aims to fill this research gap. We use three different categories of indicators as proxies for the three social capital facets described by Nahapiet and Ghoshal (1998). First, we look at the degree of individualization of a society as a proxy for the extent to which the formation of social capital structures (i.e., the formation of relationships between individuals, the configuration of their networks, their network connectivity, density, etc.) is facilitated. Second, we look at generalized trust as a measure of how easy relational social capital can be formed. Third, we look at the fractionalization of different societies to get an approximation of how easy cognitive social capital may be developed in those societies. We use data from MFIs active in 100 countries to investigate the relationship between these three categories of proxies and the financial and social performance of MFIs.

The remainder of this paper is structured as follows. "Social Capital and the Performance of MFIs" section gives an overview of the importance of social capital for the success of microfinance, whereas "Hypotheses" section develops our hypotheses. The data and empirical methodology used are presented in "Methodology and Data" section. The descriptive statistics are discussed in "Descriptive Statistics" section, followed by the presentation of the results of the econometric analysis in "Econometric Results" section. "Summary and Concluding Remarks" section concludes.

\section{Social Capital and the Performance of MFIs}

MFIs offer a range of financial services to poor households and small businesses (SMEs). The most important of these services is lending. Just like commercial banks, MFIs are confronted with asymmetric information with respect to the repayment capacity and/or repayment willingness of their potential borrowers. These borrowers have better information about the quality of the projects in which they invest the money they receive from the MFI, allowing them to make a better judgment of the probability of loan repayment. Commercial banks as well as MFIs try to reduce the problem of asymmetric information using various mechanisms. Commercial banks invest in screening and monitoring practices by collecting and evaluating hard information, such as formal records on assets and liabilities, income statements, salary specifications. In addition, they usually demand valuable collateral. Moreover, in countries with a well-developed law and property right system, they may recover the loan by going to court once a loan is not repaid.

MFIs use different methods to reduce problems of asymmetric information as they mostly deal with borrowers who are poor and have small loans. Screening and monitoring of this type of clients is generally costly due to the fixed cost nature of these activities. Moreover, information regarding these borrowers is opaque and more difficult to evaluate as formal records on assets and liabilities, salary, etc., are usually non-existent. In addition, poor borrowers and SMEs have no valuable physical collateral. Finally, MFIs are usually active in countries with an under-developed law and property right system, which makes it difficult to recover the loan by going to court.

MFIs solve problems of asymmetric information using soft information. One strategy to collect soft information is to have loan officers visit potential and existing clients to verify repayment capacity and probability, as well as to collect interest payments and repayment of the loan. The direct contact these loan officers have with their clients reduces asymmetric information problems. Through frequent interactions, loan officers may also accumulate social capital in their relationships with their clients. This leads to higher reciprocity, and, thus, to less opportunistic behavior and higher repayment willingness.

Another strategy MFIs frequently use is providing loans to groups of borrowers instead of individuals. In the context of the so-called group-lending model, group members are jointly liable to repay the loans taken up by individual group members. This provides incentives to group members to screen and monitor each other as the group's repayment determines the contributions individuals have to make to repay existing loans and/or have access to future loans. Since group members usually live close to each other in villages or urban districts, they are closely connected through social networks. These social networks provide the necessary soft information based on which screening and monitoring can be carried out effectively, thus reducing asymmetric information. Moreover, the networks provide a context allowing group members to enforce loan repayment of fellow group members. Group lending with joint liability can be seen as a substitute for the need to invest in screening and monitoring by the MFI. This lending model creates the so-called social collateral, 
which helps improving the repayment of the borrowers of these institutions.

Thus, the lending techniques used by MFIs are based on exchange relations where social capital plays an important role. These techniques are used because for most of their clients MFIs are confronted with information opacity, i.e., they have to deal with the lack of widely available and transparent information on the characteristics of their clients. Social capital makes transactions possible in such an environment. Borrowers living in environments that stimulate and facilitate the social capital accumulation may thus have higher stocks of social capital that they can use to substitute for lack of hard information and valuable physical collateral. Therefore, based on our discussion of the mechanisms underlying the provision of microfinance to poor households and SMEs, we expect that MFIs active in environments conducive to social capital development have better financial and social performance.

Several papers have investigated the importance of social capital in explaining the repayment performance of microfinance clients. The majority of these studies find a positive relationship between social capital and repayment, although there are some notable exceptions. Wydick (1999) uses information from an MFI in Guatemala and focuses on the extent to which group members know each other before they enter a borrowing group, whether they are friends, and/or whether they partake in joint social activities as measures of social ties between group members. He does not find evidence that stronger social ties are associated with better repayment performance of borrowers. Hermes et al. (2005) focus on microfinance in Eritrea and use similar measures of social ties. Their research shows that social ties help group leaders to improve their screening and monitoring efforts, resulting in lower incidences of repayment problems of group members. Karlan's (2007) study is situated in Peru and measures social ties by looking at the extent to which group members share the same culture and/or live more closely to each other. His analysis suggests that social ties measured in this way are associated with better repayment performance. Ahlin and Townsend (2007) use survey data from borrowers of BAAC, an MFI in Thailand. Their measure of social ties (they label this as cooperation) focuses on the extent to which group borrowers are willing to share money and free labor, and to what extent they are willing to coordinate the transportation of crops, the purchase of inputs, and sales of crops. They find a negative association between ties and repayment, a result that has not been reported in other studies. According to Ahlin and Townsend (2007), social ties may improve repayment when these ties help strengthening the effective use of penalties against those group members who fail to repay, whereas it reduces repayment in cases ties discourage the use of such penalties. Cassar et al. (2007), using survey data from borrowers in South Africa and Armenia, measure social capital within borrowing groups by focusing on group homogeneity and intra-group trust, and show that both these measures are positively associated with repayment performance. In a series of studies, Dufhues et al. (2011a, b, 2012, and 2013) measure social capital based on social network analysis, using information from borrowing households in Thailand and Vietnam. The results of these studies suggest that social capital is associated with better repayment performance, depending on the nature of social ties between individuals. Wydick et al. (2011) is one of the few studies focusing on how social capital can help increasing the social performance of MFIs. In particular, they show that religious networks are important for rural households in Guatemala to have access to credit.

The above-mentioned studies all use data from a single country context (except Cassar et al. 2007, who use data from two countries). They do not allow for looking at country variations in terms of how social capital development is facilitated. Recently, a small number of studies has emerged that focus on various social measurements, such as trust or culture. Burzynska and Berggren (2015) focus on the relationship between trust and a collectivist cultural dimension, and the financial performance (i.e., repayment rates, costs, and interest rates) of MFIs. Using information for 331 MFIs in 37 countries for the period 2003-2011, they find that MFIs in countries with higher levels of trust and/or a more collectivist culture on average have lower costs and lower interest rates. Manos and Tsytrinbaum (2014) focus on different measures of culture as determinants of financial and social performance. They use data for 852 MFIs from 30 countries during the period 2000-2010 and find that culture is a significant determinant of MFI financial and social performance and that the strength of the association between culture and performance depends on the type of cultural values and beliefs. Sundeen and Johnson (2012) investigate to what extent social capital (defined by them as social networks, norms, and trustworthiness) affects financial and social performance of MFIs. Their sample covers almost 2000 MFI in 115 countries between 1995 and 2011. The results suggest that social capital does affect MFI performance and that there is a trade-off between financial and social performance. Aggarwal et al. (2015) focus on analyzing whether social dimensions (i.e., trust and culture) influence the extent to which MFIs lend to female borrowers. They find that in low-trust countries MFIs lend more to women as compared to MFIs in high-trust countries. This suggests that MFIs use targeting women as borrowers as a lending strategy to substitute for the low level of trust in a society, as women are generally seen as more trustworthy borrowers. Finally, in a related study Mersland et al. (2013) 
focus on the religious background of MFIs and their performance. Using data from a sample of 405 MFIs operating in 73 countries from 2001 to 2010, they find that MFIs with a Christian background have significantly lower funding costs and consistently underperform in terms of financial profit indicators as compared to secular MFIs. In terms of loan repayment performance and average loan size (a measure of outreach), both types of MFIs perform the same, however.

We build on these recent cross-country studies analyzing the relationship between social determinants such as trust and cultural dimensions, and MFI performance. To explain how MFI performance is determined by social capital, we start from the framework developed by Nahapiet and Ghoshal (1998), which integrates the different facets of social capital to define it in terms of three distinct dimensions: structural social capital, relational social capital, and cognitive social capital. Structural social capital refers to the overall pattern of connections between individuals (the presence or absence of social ties between individuals, the network configuration, the network density, connectivity, etc.). Relational social capital describes the personal relationship that individuals develop through multiple social interactions over time, such as respect, friendship, sociability, approval, and prestige. Cognitive social capital reflects the shared norms, languages, systems of meaning, and the shared narratives.

While structural social capital encapsulates the characteristics of the social structure, relational and cognitive social capital constitute the aspects that facilitate the actions and interactions of individuals within the social structure. Thus, social capital is embedded in social structures and is owned jointly by the members of the social structure (i.e., no member can unilaterally own her/ his social structure).

\section{Hypotheses}

In this section, we propose concrete social determinants to measure the three social capital dimensions identified by Nahapiet and Ghoshal (1998), and develop our hypotheses on the expected relationships between these determinants and the MFI financial and social performance.

We expect a positive association between the financial and social performance of MFIs and the social dimensions that facilitate the social capital formation. As explained in "Social Capital and the Performance of MFIs" section, unlike traditional banking, MFIs give access to loans to asset-poor individuals by allowing them to replace the physical collateral by their social capital. By relying on social capital, repayment of loans is improved, which positively contributes to the financial performance of
MFIs. Moreover, relying on social capital allows them to be more socially oriented (which at least formally is their primary mission), as the availability of social collateral reduces the information opaqueness that is generally associated with providing financial services to poorer borrowers, i.e., they can better lend smaller loans as compared to traditional banks, and can better reach the asset-poor individuals without access to traditional banks (with a particular focus on women). Thus, we expect MFIs to perform better, both financially and socially, in societies where social capital formation is facilitated. Individuals living in societies where the development of social capital is hampered may not have the necessary stocks of social capital to ensure the success of microcredit. Hence, we expect lower financial performance of MFIs active in these societies. At the same time, due to the lack of reliable stocks of social capital, MFIs may get a more commercially oriented focus and may not be able to reach their intended social aims (i.e., to lend lower loan amounts to mainly women).

As for the outcome variables, we focus on three dimensions of social and financial performance, i.e., the share of female borrowers, the average loan size relative to GNI per capita, and the operational self-sufficiency. The first two measures relate to social performance, the third is a measure of financial performance of MFIs. A higher value for the operational self-sufficiency ratio is associated with better financial performance of MFIs. If MFIs provide more loans to women and/or if they provide smaller loans, this is seen as showing better social performance. These financial and social performance measures, although not perfect, are standard in the microfinance literature (see, e.g., Ahlin et al. 2011; Hermes and Meesters 2011; Manos and Tsytrinbaum 2014).

To investigate how easy/difficult social capital can be formed in different environments, we look at the following three dimensions: fractionalization of society, generalized trust, and individualism. The fractionalization of different societies may lead to disparities in terms of how easy/ difficult cognitive social capital (shared codes and languages, shared narratives) can be formed. The generalized trust proxies the formation of relational social capital as a function of social interaction. We take the individualism index as a measure for the extent to which formation of social capital structures (i.e., the formation of relationships between individuals, the configuration of their networks, their network connectivity, density, etc.) is facilitated in a society.

\section{Fractionalization}

Fractionalization of society refers to the probability that two randomly drawn individuals coming from the same 
country are not from the same ethnic, religious, or linguistic group. The higher this probability, the higher is the level of fractionalization. In the economic growth literature, fractionalization is associated with political instability, weak institutions, and poor macroeconomic performance. Fractionalization is expected to reduce the development of cognitive social capital (Nahapiet and Ghoshal 1998). When a society is highly fractionalized, this means that a large number of linguistic, religious, and/ or ethnic groups live together. The differences between groups in such a society may lead to smaller in-group networks and distrust of one group versus other groups. Moreover, beliefs, norms, and values may differ between groups as well. Vaessen and Bastiaensen (1999) argue that when local social structures are sufficiently integrated, norms, perceptions, and ideologies can circulate freely among the different social actors, thus leading to positive social capital accumulation. Hence, homogeneity of local social structures, or low fractionalization, may contribute to developing structural social capital and support economic growth.

Based on this discussion of the association between fractionalization and social capital formation, in combination with our expectation that higher levels of social capital are associated with better financial and social performance of MFIs, we hypothesize that lower fractionalization leads to better financial and social performance. As MFIs' social and financial performance relies on the social capital pledged by their borrowers, we expect a negative relationship between fractionalization and MFI financial and social performance. First of all, fractionalized societies are likely to produce lower stocks of social capital, which renders the social collateral-backed lending less successful. Thus, in these societies it may be less likely for the threat of a social sanction in case of delinquent behavior to be credible, which reduces the probability of loan repayments. Moreover, less social collateral also means less social support in case of economic problems, again reducing the probability that borrowers will pay back their loans. This leads to the expectation that MFIs may achieve worse-off financial performance in fractionalized societies. Second, because the availability of social collateral reduces the information opaqueness that is associated with providing financial services to poorer borrowers, MFIs active in fractionalized countries may be less successful in achieving social goals. In other words, we expect that MFIs in lessfractionalized countries can reach more women with lower loan sizes than MFIs that are active in fractionalized countries.

Thus, we derive the following hypotheses:

H1a Operational self-sufficiency is negatively associated with fractionalization (i.e., linguistic, ethnic, religious);
H1b Female borrowing is negatively associated with fractionalization (i.e., linguistic, ethnic, religious); and

H1c The loan size is positively associated with fractionalization (i.e., linguistic, ethnic, religious).

\section{Generalized Trust}

Generalized trust is defined as trust towards strangers, which arises when "... a community shares a set of moral values in such a way as to create regular expectations of regular and honest behavior" (Fukuyama 1995). Generalized trust is different from particularized trust, because it is extended to people "... on whom the trusting part has no direct information" (Bjørnskov 2006). The extent to which generalized trust is prevalent in a society is expected to be positively associated with developing relational social capital. In particular, we expect that higher levels of generalized trust are conducive to a faster development of friendships through social interactions, higher levels of respect and acceptance between individuals, and swifter sociability among individuals. Indeed, Realo and Allik (2009) point out that when trust “... is limited to the nuclear family or kinship alone, people have lower levels of social capital. Social capital increases as the radius of trust widens to encompass a larger number of people and social networks, ridging the 'gap' between the family and state." Knack and Keefer (1997) show there is a positive association between trust and social capital.

If we combine these findings regarding the association between generalized trust and social capital formation with our discussion regarding the relationship between social capital and the financial and social performance of MFIs, we may develop the following hypotheses:

H2a Operational self-sufficiency is positively associated with generalized trust;

H2b Female borrowing is positively associated with generalized trust; and

H2c The loan size is negatively associated with generalized trust.

In other words, we expect that the social capital backed lending model performs better (both in terms of financial and social objectives) in societies where the development of relational social capital is facilitated.

\section{Individualism}

Next, we look at individualism as a proxy for how easy/ difficult structural social capital (i.e., social networks) can be formed within a society. Individualism is one of several dimensions of the cultural setting of a society, which has 
been developed by Hofstede (2001). ${ }^{4}$ According to Hofstede (2001) culture refers to the collective programming of the mind that distinguishes members of one group from another. It defines what represents acceptable and/or desirable behavior within the group and accordingly can help group members make decisions and/or judge the decisions of others. As explained by Peña López and Sánchez Santos (2014, p. 700), culture “...is a subliminal system of thought that reflects the organizations of values, norms and symbols of a particular society ...[influencing] the interactions and choices of individuals (Parsons and Shills 1990)." These interactions and choices take place within the context of the networks and relationships between individuals, i.e., the social structure. Culture, social structure, and social networks are therefore closely related phenomena.

Related to this, Inkeles (2000) states that Hofstede's cultural dimensions are related to social capital and that this is particularly true for individualism. In a similar vein, Allik and Realo (2004), and Realo and Allik (2009) argue that the possibility to act individualistically is an important driver of the configuration of his/her social capital. In individualistic societies, it is expected that the individual looks after himself/herself and his/her immediate family only. In these societies, individuals focus on themselves rather than on the group to which they belong when they develop their networks. As a consequence, individuals in these societies will develop their social networks according to their own interest, i.e., they are not bound by social norms to restrict their social interactions within their kin. Individualism therefore is associated with a preference for a loosely knit and broadly developed social network. In contrast, collectivist societies rely on values and beliefs that strongly link people into cohesive in-groups where the group members are expected to protect each other throughout their lifetime in exchange of unquestioning loyalty. These common collectivist visions lead to smaller, tightly knit social frameworks where individuals focus on the group rather than on themselves. ${ }^{5}$

Based on the above discussion, we expect that individuals coming from individualist societies have created networks beyond their kin, and are therefore likely to be more successful in developing wider social networks as compared to individuals coming from collectivist societies. As MFI financial and social performance relies on the stocks

\footnotetext{
${ }^{4}$ Although Hofstede (2001) distinguishes six dimensions of culture, we focus on individualism, because as we will discuss below, in the literature the relationship between individualism and social capital has been discussed explicitly. This does not hold for the other dimensions of culture.

5 The definitions of individualism is taken from the website developed by Geert Hofstede; see http://geert-hofstede.com/national-culture. html.
}

of social capital of microcredit borrowers, we expect that MFIs perform better in individualistic societies. The individualism index we use in this paper indicates the degree to which a given society can be considered as individualistic. High individualism values indicate that the society is encouraging individuals to focus on personal achievement and develop valuable social ties/networks.

The above discussion suggests the following hypotheses:

H3a Operational self-sufficiency is positively associated with the extent to which a society can be characterized as individualistic;

H3b Female borrowing is positively associated with the extent to which a society can be characterized as individualistic; and

H3c The loan size is negatively associated with the extent to which a society can be characterized as individualistic.

\section{Methodology and Data}

The empirical methodology we follow is inspired by the work of Ahlin et al. (2011), who investigate the determinants of the MFI financial performance by looking at three categories of independent variables, i.e., macroeconomic variables, formal institutional variables, and MFI-specific variables. In our analysis for this paper, we add a fourth category, i.e., our three types of social dimensions. The baseline model can be written as follows:

$$
\begin{aligned}
& Y_{i j t}=\propto+\beta_{M} M_{i j t}+\beta_{0} X_{0 j t}+\beta_{1} X_{1 j t}+\beta_{2} X_{2 j t} \\
& +\beta_{\text {income } \text { Income }_{j t-1}+\beta_{\text {income }^{2}} \text { Income }_{j t-1}^{2}} \\
& +\beta_{\text {age }} \mathrm{Age}_{j t}+\beta_{\mathrm{age}^{2}} \mathrm{Age}_{j t}^{2}+\varepsilon_{i j t},
\end{aligned}
$$

where $Y_{i j t}$ is a vector of performance outcome measures of MFI $i$ in year $t$, located in country $j$. As was already mentioned in "Hypotheses" section with respect to the outcome variables, we focus on the share of female borrowers, the average loan size relative to GNI per capita, and the operational self-sufficiency. The first two measures relate to social performance, and the third is a measure of financial performance of MFIs. A higher value for the operational self-sufficiency ratio is associated with better financial performance of MFIs. If MFIs provide more loans to women and/or if they provide smaller loans, this is seen as showing better social performance. $M_{i j t}$ is a vector of MFI-specific control variables of MFI $i$ in country $j$ at time $t ; X_{0 j t}$ is a vector of macroeconomic variables describing country $j$ at time $t ; X_{1 j t}$ is a vector of variables describing the formal institutional environment from country $j$ at time 
$t$; and $X_{2 j}$ is the vector containing our variables of interest, i.e., the social dimensions describing country $j$.

The MFI-specific variables included in the analysis are the MFI age, the number of borrowers, and the ratio of assets to loan portfolio (reflecting the degree to which non-loan assets are supporting the MFI's lending operation), as well as the MFI's geographical location (i.e., dummy measuring whether the MFI is from Latin America or the Caribbean or from another part of the world). The data related to MFIs come from Mix Market, a publicly available web-based data source, which provides detailed information with respect to the financial and social performance of MFIs around the world. Currently, this database contains information for over 2000 MFIs with information going back as far as the mid1990s. Following Ahlin et al. (2011) and others in the field of microfinance research, we only use data for MFIs that have been rated with four and five diamonds in the Mix Market dataset. These diamonds indicate the quality of the financial statements of MFIs as published by the Mix Market, five diamonds being the highest level of quality (i.e., the financial statements are audited by a recognized auditing company). We collect data for MFI-specific characteristics for the period 1996-2012. The final dataset consists of 6934 observations covering 934 MFIs based in 100 countries.

The macroeconomic variables include the annual growth of the real GDP per capita, the quadratic term of the real GDP per capita, the share of manufacturing in total GDP, measured in terms of the value added of this sector, the total labor force as a percentage of the total population over 15 years, the share of the industrial sector in total GDP (in terms of value added), the share of services in total GDP (in terms of value added), the annual inflation rate, and net foreign direct investment inflows as a percentage of total GDP. The choice for these variables is based on what has been used in other related studies (e.g., Ahlin et al. 2011; Hermes and Meesters 2011). Information for the macroeconomic variables is collected from the World Development Indicators (WDI).

With respect to the formal institutional variables, we use a measure of the political stability and absence of violence, a measure for the control of corruption, as well as a measure of the rule of law, all measured at the country level. Again, our choice of variables has been guided by the existing literature. Data for the formal institutional variables indicators come from the Kaufmann World Governance Indicators database. The Kaufmann indicators are available since 1996. Between 1996 and 2002, the data are only available bi-annually. We therefore use interpolation to create observations for the years data are not available. ${ }^{6}$

\footnotetext{
${ }^{6}$ So, for example for the year 1997, we create observations for the formal institutional variables, by calculating the average value of a variable based on the observations for 1996 and 1998.
}

With respect to our variables of interest, we include three types of social dimensions, i.e., fractionalization, generalized trust, and individualism. We take three different measures for country-level fractionalization from Alesina et al. (2003). These authors developed a dataset measuring ethnic, linguistic, and religious fractionalization within a country. With respect to generalized trust, we follow most of the literature and use a measure of the socalled generalized trust, which is available in the World Value Survey (WVS). Generalized trust is measured in the WVS by asking the following question: "In general, do you think that most people can be trusted, or can't you be too careful in dealing with people?" As was discussed above, we also use Geert Hofstede's individualism index. The data for this index are taken from Hofstede's Cultural Dimensions Data Matrix. ${ }^{7}$

Following Ahlin et al. (2011), we start by using a small set of specifications as a source of discipline. ${ }^{8}$ We then perform the tests by including larger sets of controls. Ahlin et al. (2011) run pooled OLS regressions followed by additional series of tests accounting for the MFI-level heterogeneity. However, we are not able to do this, as our variables of interest are time invariant. The characteristics of our data direct our estimation strategy. Random effects are not suitable either as it assumes that the individualspecific effects are distributed independently of the independent variables. It is reasonable to assume that we have dependencies in our data as we have nested data (MFIs nested within countries). The Hausman-Taylor estimator for error-components model is also not suitable, as we do not have instruments for our potentially endogenous variables and our variables of interest are time invariant. We thus rely on OLS estimations with Huber-White heteroscedastic-consistent standard errors, and we perform a wide range of additional robustness checks, acknowledging that we are unable to fully deal with the endogeneity concerns. ${ }^{9}$ However, since social dimensions only change very slowly over time and given the fact that our panel data are relatively short, we have reasons to assume that in our case the endogeneity problem may be less severe.

In additional tests, we use standard errors clustered at the country level. Furthermore, to address the outlier issues

\footnotetext{
7 The data were retrieved from the following website: http://www. geerthofstede.nl/dimension-data-matrix. We do not use the data from the GLOBE project. As is shown in the study by Manos and Tsytrinbum (2014) using these data dramatically reduces the number of countries for which the analysis can be carried out.

8 Table 2 provides definitions of all variables used in our analysis.

${ }^{9}$ We prefer using OLS estimations with Huber-White heteroscedastic-consistent standard errors, instead of using simple pooled OLS regressions. The reason is that using pooled OLS regressions may lead to an overly optimistic picture of the estimation outcomes, because given the content and structure of our dataset the standard OLS assumptions may be violated.
} 
we re-run our estimates on a trimmed sample and use conditional median estimations. ${ }^{10}$ Finally, because our data for the period 1996-2005 is highly unbalanced, we also perform the estimations on the subset of data between 2006 and 2012.

\section{Descriptive Statistics}

Table 1 shows the number of MFIs for which we have data in a particular year (between 1996 and 2012). As it is clear from this table, the bulk of the information on MFIs is available for the years 2006-2011. For the first 4 years, the number of observations is equal to or less than 100 per year. These numbers indicate that the dataset we have is unbalanced. This is the case for many papers using the Mix Market dataset. Table 2 provides an overview of the descriptive statistics of the variables we use in the empirical analysis. The table shows that the number of observations significantly varies between the different variables. In particular, data for Hofstede's individualism dimension are not available for all countries in our dataset. In total, Hofstede's matrix contains data on individualism for 78 countries. When we further combine the Hofstede data on individualism with the data on MFIs from Mix Market, we are left with only 23 countries.

With respect to our dependent variables, the descriptive statistics show that the MFIs in our sample mainly lend to women: two-thirds of the loans is provided to female borrowers. This supports the idea that the general approach taken by MFIs is to focus their lending on women as they are considered to perform better in terms of repayment, while at the same time making a greater social impact (Aggarwal et al. 2015). The size of the average loan provided by an MFI in a particular country is two-thirds the size of the average GNI per capita of that country. Finally, the average MFI in our sample appears to be financially sustainable as the mean of the operational self-sustainability variables is above 1 .

Table 3 shows the correlation matrix. The table suggests that our financial and social performance variables do correlate with several of the social dimensions we focus on. Moreover, several of the correlation coefficients do seem to have the expected positive sign. This is the first indication that there may be a positive association between the financial and social performance of MFIs and the social dimensions conducive to developing social capital/ties. The

\footnotetext{
10 Thus, we also report our estimates using conditional median regression, which minimizes the sum of absolute residuals rather than the squared residuals and tends to be less susceptible to outlier problems than least squares; see also Ahlin et al. 2011).
}

Table 1 Number of observations in the dataset Source: Calculation by the authors based on data from Mix Market

\begin{tabular}{lc}
\hline Year & $\begin{array}{l}\text { Number of } \\
\text { observations }\end{array}$ \\
\hline 1996 & 21 \\
1997 & 44 \\
1998 & 69 \\
1999 & 100 \\
2000 & 138 \\
2001 & 168 \\
2002 & 249 \\
2003 & 355 \\
2004 & 455 \\
2005 & 543 \\
2006 & 634 \\
2007 & 676 \\
2008 & 762 \\
2009 & 837 \\
2010 & 916 \\
2011 & 846 \\
2012 & 121 \\
Total & 6934 \\
\hline &
\end{tabular}

next step is to find out whether this association holds in the setting of a multivariate analysis. ${ }^{11}$

\section{Econometric Results}

We first focus on measures of societal fractionalization and generalized trust and their association with financial and social performance of MFIs. The association between individualism and the financial and social performance of MFIs will be discussed separately, as the dataset we are able to apply for this measure is much smaller due to lack of data on cultural measures for a considerable number of countries in our dataset. We do not estimate a full model incorporating all these social dimensions, because by doing so we would lose too many observations. Moreover, in this way we also avoid potential problems of multicollinearity.

The results of our empirical analysis using measures of societal fractionalization and generalized trust are

\footnotetext{
11 We cannot include the variables Geographic (indicating whether the country is from Latin America or Caribbean or not) and GDP per capita in the same regression models as the correlation between these two variables appears to be relatively high (see the correlation matrix, Table 3). Moreover, when adding the covariates one by one, the two variables (i.e., Geographic and real GDP per capita) switch signs, indicating potential multicollinearity problems. To decide what variable to keep, we performed the regressions with the two variables included separately and we selected the real GDP per capita as it brought the highest explanatory power based on the adjusted $\mathrm{R}$-squared value.
} 
Table 2 Descriptive statistics

\begin{tabular}{|c|c|c|c|c|c|c|}
\hline Variable & Description & $n$ & Mean & SD & Min & $\operatorname{Max}$ \\
\hline \multicolumn{7}{|l|}{ Dependent variables } \\
\hline ShareFemBorr & $\begin{array}{l}\text { Share of female borrowers: number of active } \\
\text { female borrowers/number of active borrowers }\end{array}$ & 5805 & 0.67 & 0.29 & 0 & 6.69 \\
\hline AvgLoanToGNIcapita & $\begin{array}{l}\text { Average loan per GNI per capita: average loan } \\
\text { balance per borrower/GNI per capita }\end{array}$ & 6619 & 0.65 & 2.08 & 0 & 94.71 \\
\hline OSS & $\begin{array}{l}\text { Operational self-sufficiency: financial revenue/ } \\
\text { (financial expense }+ \text { loan loss provision } \\
\text { expense }+ \text { operating expense) }\end{array}$ & 6734 & 1.17 & 0.71 & -0.29 & 36.63 \\
\hline \multicolumn{7}{|l|}{ MFI controls } \\
\hline MFI_AGE & $\begin{array}{l}\text { Age of the MFI (years): calculated as the year of } \\
\text { the observation - the year when the MFI was funded }\end{array}$ & 6680 & 12.23 & 9.3 & 1 & 62 \\
\hline NoBorrLag_LN & Ln of number of borrowers (lagged) & 5682 & 9.3 & 1.8 & 0.69 & 15.92 \\
\hline AssetsPerGLP_LagLN & Ln of Assets per GLP (lagged) & 5848 & 0.33 & 0.36 & -3.22 & 4.91 \\
\hline Geographic & $\begin{array}{l}1 \text { if country is from Latin America or the } \\
\text { Caribbean, } 0 \text { otherwise }\end{array}$ & 6934 & 0.34 & 0.47 & 0 & 1 \\
\hline \multicolumn{7}{|l|}{ Macroeconomic indicators } \\
\hline GrowthGDPcapitaPPP & Annual growth in real GDP per capita & 6645 & 9.12 & 10.73 & -47.85 & 138.19 \\
\hline GDPperCapitaPPP_Lag & Real GDP per capita (lagged) & 5751 & 4550.15 & 3294.32 & 255.75 & $18,087.44$ \\
\hline Manufacturing & Manufacturing, value added ( $\%$ GDP) & 6425 & 15.69 & 6.24 & 0 & 96.58 \\
\hline Workforce & Labor force/population aged $15+$ & 5816 & 67.86 & 9.5 & 39.6 & 90.8 \\
\hline Industry & Industry, value added (\% of GDP) & 6465 & 30.35 & 9.24 & 4.84 & 100 \\
\hline Inflation & Inflation, consumer prices (annual \%) & 6574 & 7.48 & 6.85 & -13.23 & 96.09 \\
\hline FDI & Foreign direct investment, net inflows ( $\%$ of GDP) & 6700 & 3.89 & 4.83 & -5.69 & 84.94 \\
\hline \multicolumn{7}{|l|}{ Formal institutions } \\
\hline PS & Political stability and absence of violence & 6761 & -0.84 & 0.7 & -3.18 & 1.27 \\
\hline RL & Rule of law & 6797 & -0.60 & 0.46 & -1.96 & 1.37 \\
\hline $\mathrm{CC}$ & Control of corruption & 6797 & -0.61 & 0.41 & -1.82 & 1.57 \\
\hline \multicolumn{7}{|l|}{ Social dimensions } \\
\hline Ethnic & Ethnic fractionalization & 6694 & 0.48 & 0.22 & 0.04 & 0.93 \\
\hline Language & Linguistic fractionalization & 6539 & 0.42 & 0.31 & 0.01 & 0.92 \\
\hline Religion & Religious fractionalization & 6697 & 0.35 & 0.2 & 0 & 0.86 \\
\hline Trust & Generalized Trust (WVS) & 4317 & 0.2 & 0.1 & 0.05 & 0.53 \\
\hline IDV & Individualism Index & 3502 & 25.3 & 13.8 & 6 & 60 \\
\hline
\end{tabular}

Based on calculations of the authors

presented in Tables 4, 5, 6, 7, 8, and 9. Tables 4, 5, and 6 show the results for the conditional mean regressions for the three dependent variables, i.e., Share of Female Borrowers (Table 4), Average Loan per GNI per Capita (Table 5), and Operational Self-Sufficiency (OSS; Table 6). The results in Table 4 generally support our hypotheses. Societal fractionalization is associated with lower shares of female borrowers, i.e., MFIs that are active in fractionalized societies on average lend less to women. Moreover, lending to women is higher in high-trust countries. The results for the average loan size (Table 5) and the OSS (Table 6) show similar patterns. Loan size is higher in countries with high societal fractionalization and in lowtrust countries, indicating lower social performance when MFIs are active in societies where cognitive and relational social capital formation is difficult. OSS is lower in countries with high societal fractionalization, suggesting worse financial performance in these contexts. ${ }^{12}$

To address potential outlier problems, we follow Ahlin et al. (2011) and estimate conditional median regression models. ${ }^{13}$ The outcomes for our social dimensions are similar to those presented in Tables 4, 5, and 6. This supports our main hypothesis that MFIs which are active in

\footnotetext{
12 We also estimated the baseline models presented in Tables 4, 5, and 6 using simple pooled OLS regressions. The results of these estimations are almost identical to those shown in the tables. The pooled OLS results have not been added to the tables in the paper, but they are available upon request from the authors.

13 We have not added these tables in the paper, but they are available upon request from the authors.
} 


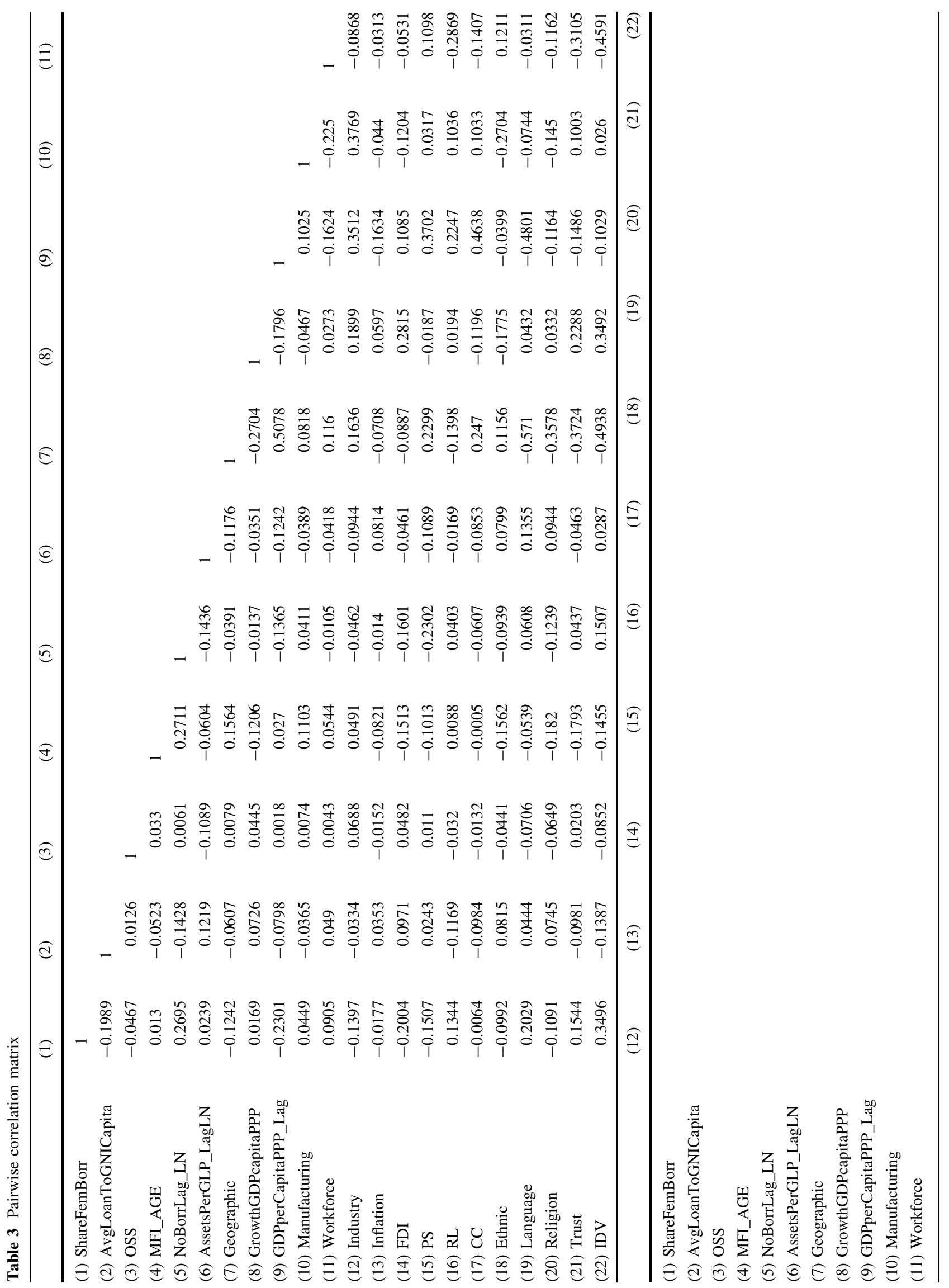




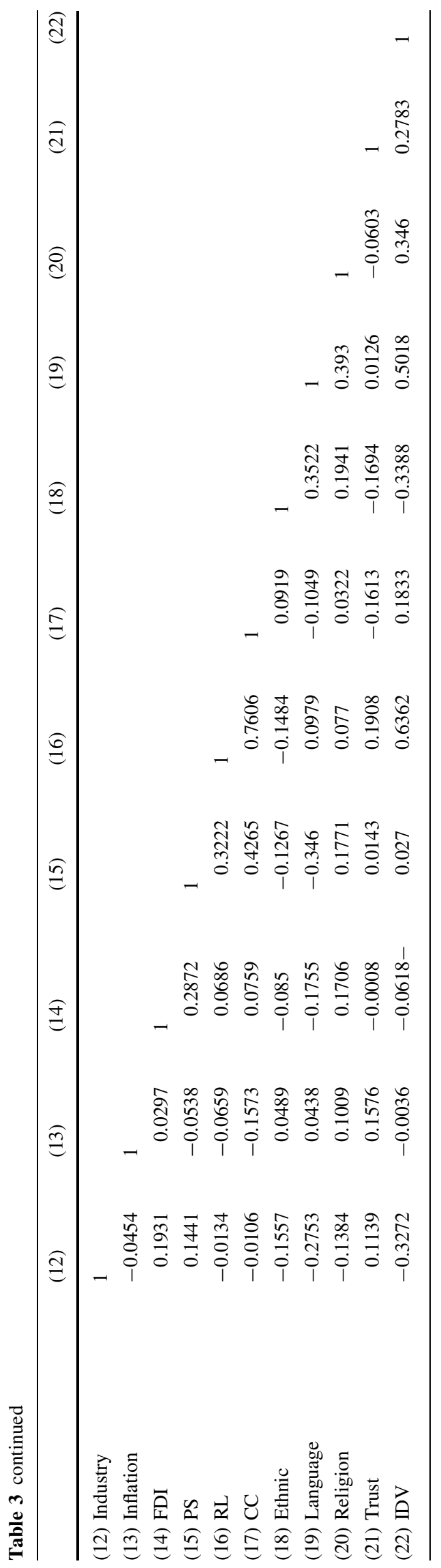

contexts conducive to developing social capital show higher financial and social performance.

As a robustness check we add the estimation results for our three measures of financial and social performance of MFIs, in which we include the three different dimensions of fractionalization simultaneously. These results are presented in the last column (column [5]) of Tables 4, 5, and 6 . The results suggest that for two performance measures (share of female borrowers and operational self-sufficiency) religious fractionalization is most important for explaining MFI performance. For the third performance measure (average loan size) ethnic fractionalization appears to be the most important explanatory dimension.

In the regression models presented in Tables 4, 5, and 6, we use a smaller set of control variables, because for some of the control variables we have left out, we have a significant number of missing values. Adding all controls leads to a drop in the number of observations for each regression model. ${ }^{14}$ Still, as a robustness test, in Tables 7 , 8 , and 9 we run the same regressions as in Tables 4,5 , and 6 , but this time we use a larger set of control variables. We should note here that in the regression models presented in Tables 4, 5, 6, 7, 8, and 9, we do not add controls that are correlated with any of our variables of interest. The results for our social dimensions remain largely unchanged as compared to the results reported in Tables 4,5 , and $6 .{ }^{15}$ Once again, therefore, these results support our main hypothesis that MFIs which are active in contexts conducive to developing social capital show higher financial and social performance.

We also redo the estimations presented in Tables 4, 5, and 6 using standard errors clustered at the country level to account for the fact that our data cover MFIs that are active in the same country. Also when we use these clustered standard errors, the results remain largely the same (although in some cases these results are no longer statistically significant). ${ }^{16}$

We then perform analyses similar to the one presented in Tables 4, 5, 6, 7, 8, and 9, but now we use a trimmed dataset. In particular, we drop the $1 \%$ top and bottom of the data to further control for the potential impact of outliers on the results. The results of these analyses are

\footnotetext{
${ }^{14}$ The number of observations used in the regression models presented in Tables 4, 5, and 6 varies between 3176 and 5805; for Tables 7, 8, and 9 these numbers are between 2788 and 4883 .

15 Due to the pairwise correlations between some of the control variables in our models, their signs and significance may change as compared to the first six tables.

16 The results of the estimations using clustered standard errors are not reported in the paper but are available on request from the authors.
} 
Table 4 Fractionalization, generalized trust, and MFI social performance (conditional mean regressions)

\begin{tabular}{|c|c|c|c|c|}
\hline Variables & $\begin{array}{l}\text { (1) } \\
\text { ShareFemBorr }\end{array}$ & $\begin{array}{l}\text { (2) } \\
\text { ShareFemBorr }\end{array}$ & $\begin{array}{l}\text { (3) } \\
\text { ShareFemBorr }\end{array}$ & $\begin{array}{l}\text { (4) } \\
\text { ShareFemBorr }\end{array}$ \\
\hline MFI_AGE & $0.00272 * * *(0.00104)$ & $0.00301 * * *(0.00107)$ & $0.00296 * * *(0.00104)$ & $0.00275 * *(0.00132)$ \\
\hline MFI_AGEsq & $-8.90 \mathrm{e}-05^{* * *}(2.23 \mathrm{e}-05)$ & $-8.30 \mathrm{e}-05^{* * *}(2.26 \mathrm{e}-05)$ & $-9.07 \mathrm{e}-05^{* * *}(2.23 \mathrm{e}-05)$ & $-6.73 \mathrm{e}-05^{* *}(2.80 \mathrm{e}-05)$ \\
\hline GrowthGDPcapitaPPP & $-0.000292(0.000413)$ & $0.000415(0.000407)$ & $0.000253(0.000401)$ & $0.000616(0.000529)$ \\
\hline GDPperCapitaPPP & $-6.82 \mathrm{e}-05^{* * *}(4.99 \mathrm{e}-06)$ & $-7.86 \mathrm{e}-05^{* * *}(5.00 \mathrm{e}-06)$ & $-7.81 \mathrm{e}-05^{* * *}(4.93 \mathrm{e}-06)$ & $-8.35 \mathrm{e}-05^{* * *}(7.03 \mathrm{e}-06)$ \\
\hline GDPperCapitaPPPsq & $3.99 \mathrm{e}-09 * * *(3.35 \mathrm{e}-10)$ & $4.61 \mathrm{e}-09 * * *(3.35 \mathrm{e}-10)$ & $4.52 \mathrm{e}-09 * * *(3.28 \mathrm{e}-10)$ & $5.07 \mathrm{e}-09 * * *(4.46 \mathrm{e}-10)$ \\
\hline Manufacturing & $0.000435(0.000795)$ & $0.00171 * *(0.000843)$ & $0.00186 * *(0.000797)$ & $0.00269 * * *(0.000982)$ \\
\hline Industry & $0.000977 *(0.000576)$ & $0.00155^{* *}(0.000605)$ & $0.00117 * *(0.000584)$ & $-0.00105 *(0.000608)$ \\
\hline Inflation & $-0.000857(0.000719)$ & $-0.000768(0.000867)$ & $0.000533(0.000876)$ & $-0.000244(0.000861)$ \\
\hline FDI & $-0.00884 * * *(0.00120)$ & $-0.00879 * * *(0.00118)$ & $-0.00783^{* * *}(0.00107)$ & $-0.0112 * * *(0.00106)$ \\
\hline PS & $-0.0550 * * *(0.00673)$ & $-0.0513 * * *(0.00704)$ & $-0.0328 * * *(0.00679)$ & $-0.0371 * * *(0.00879)$ \\
\hline RL & $0.122 * * *(0.00888)$ & $0.140 * * *(0.00948)$ & $0.140 * * *(0.00891)$ & $0.115 * * *(0.0134)$ \\
\hline Ethnic & $-0.157 * * *(0.0195)$ & & & \\
\hline Language & & $-0.0250(0.0160)$ & & \\
\hline Religion & & & $-0.213 * * *(0.0222)$ & \\
\hline Trust & & & & $0.207 * * *(0.0682)$ \\
\hline Constant & $0.967 * * *(0.0258)$ & $0.893 * * *(0.0286)$ & $0.971 * * *(0.0271)$ & $0.929 * * *(0.0436)$ \\
\hline Observations & 5012 & 4894 & 4987 & 3176 \\
\hline
\end{tabular}

Dependent variable: Share of female borrowers. All estimations are based on using Huber-White heteroscedasticity-consistent standard errors. Standard errors are in parentheses

$* * * p<0.01, * * p<0.05, * p<0.1$

Table 5 Fractionalization, generalized trust, and MFI social performance (conditional mean regressions)

\begin{tabular}{|c|c|c|c|c|}
\hline Variables & $\begin{array}{l}\text { (1) } \\
\text { AvgLoanToGNIcapita }\end{array}$ & $\begin{array}{l}\text { (2) } \\
\text { AvgLoanToGNIcapita }\end{array}$ & $\begin{array}{l}\text { (3) } \\
\text { AvgLoanToGNIcapita }\end{array}$ & $\begin{array}{l}\text { (4) } \\
\text { AvgLoanToGNIcapita }\end{array}$ \\
\hline MFI_AGE & $-0.0244 * * *(0.00940)$ & $-0.0261 * *(0.0105)$ & $-0.0282 * * *(0.0104)$ & $-0.0160 * * *(0.00362)$ \\
\hline MFI_AGEsq & $0.000643 * * *(0.000192)$ & $0.000592 * * *(0.000202)$ & $0.000649 * * *(0.000201)$ & $0.000323^{* * *}(6.94 \mathrm{e}-05)$ \\
\hline GrowthGDPcapitaPPP & $0.0170 *(0.00905)$ & $0.0129(0.00854)$ & $0.0129(0.00850)$ & $0.00394 *(0.00226)$ \\
\hline GDPperCapitaPPP & $-0.000134 * * *(2.86 \mathrm{e}-05)$ & $-5.39 \mathrm{e}-05^{* *}(2.65 \mathrm{e}-05)$ & $-9.05 \mathrm{e}-05^{* * *}(2.52 \mathrm{e}-05)$ & $-7.54 \mathrm{e}-06(1.60 \mathrm{e}-05)$ \\
\hline GDPperCapitaPPPsq & $7.18 \mathrm{e}-09^{* * *}(2.01 \mathrm{e}-09)$ & $3.03 \mathrm{e}-09 *(1.78 \mathrm{e}-09)$ & $4.75 \mathrm{e}-09^{* * *}(1.76 \mathrm{e}-09)$ & $-1.31 \mathrm{e}-09(9.69 \mathrm{e}-10)$ \\
\hline Manufacturing & $0.0196 *(0.0119)$ & $0.0123(0.0111)$ & $0.0110(0.0110)$ & $0.00282(0.00429)$ \\
\hline Industry & $-0.00959 * *(0.00374)$ & $-0.0116 * * *(0.00389)$ & $-0.0102 * * *(0.00384)$ & $-0.00490 *(0.00277)$ \\
\hline Inflation & $0.00720(0.00621)$ & $0.00980(0.00779)$ & $0.00783(0.00776)$ & $0.00234(0.00318)$ \\
\hline FDI & $0.0352 * * *(0.00977)$ & $0.0346 * * *(0.0101)$ & $0.0307 * * *(0.00977)$ & $0.0320 * * *(0.00462)$ \\
\hline PS & $0.300 * * *(0.0422)$ & $0.326 * * *(0.0481)$ & $0.216 * * *(0.0414)$ & $0.180 * * *(0.0211)$ \\
\hline RL & $-0.605 * * *(0.0845)$ & $-0.776 * * *(0.105)$ & $-0.684 * * *(0.0951)$ & $-0.251 * * *(0.0357)$ \\
\hline Ethnic & $1.017 * * *(0.162)$ & & & \\
\hline Language & & $0.515 * * *(0.105)$ & & \\
\hline Religion & & & $0.530 * * *(0.121)$ & \\
\hline Trust & & & & $-0.779 * * *(0.139)$ \\
\hline Constant & $0.210(0.206)$ & $0.399 * *(0.179)$ & $0.526 * * *(0.161)$ & $0.735 * * *(0.0943)$ \\
\hline Observations & 5715 & 5575 & 5682 & 3728 \\
\hline
\end{tabular}

Dependent variable: Average loan per GNI per capita. All estimations are based on using Huber-White heteroscedasticity-consistent standard errors. Standard errors in parentheses

$* * * p<0.01, * * p<0.05, * p<0.1$ 
Table 6 Fractionalization, generalized trust, and MFI financial performance (conditional mean regressions)

\begin{tabular}{|c|c|c|c|c|}
\hline Variables & $\begin{array}{l}\text { (1) } \\
\text { OSS }\end{array}$ & $\begin{array}{l}\text { (2) } \\
\text { OSS }\end{array}$ & $\begin{array}{l}\text { (3) } \\
\text { OSS }\end{array}$ & $\begin{array}{l}(4) \\
\text { OSS }\end{array}$ \\
\hline MFI_AGE & $0.0101 * * *(0.00275)$ & $0.00965 * * *(0.00269)$ & $0.00962 * * *(0.00256)$ & $0.00847 * *(0.00370)$ \\
\hline MFI_AGEsq & $-0.000192 * * *(5.75 \mathrm{e}-05)$ & $-0.000178 * * *(5.82 \mathrm{e}-05)$ & $-0.000182 * * *(5.65 \mathrm{e}-05)$ & $-0.000138^{*}(7.98 \mathrm{e}-05)$ \\
\hline GrowthGDPcapitaPPP & $0.00193 * *(0.000926)$ & $0.00223 * *(0.00101)$ & $0.00221 * *(0.00101)$ & $7.66 \mathrm{e}-05(0.00152)$ \\
\hline GDPperCapitaPPP & $2.92 \mathrm{e}-05 * * *(1.02 \mathrm{e}-05)$ & $1.53 \mathrm{e}-05(1.24 \mathrm{e}-05)$ & $2.03 \mathrm{e}-05^{*}(1.10 \mathrm{e}-05)$ & $2.31 \mathrm{e}-05(1.66 \mathrm{e}-05)$ \\
\hline GDPperCapitaPPPsq & $-2.46 \mathrm{e}-09 * * *(7.54 \mathrm{e}-10)$ & $-1.89 \mathrm{e}-09 * *(8.19 \mathrm{e}-10)$ & $-2.01 \mathrm{e}-09 * *(7.86 \mathrm{e}-10)$ & $-2.31 \mathrm{e}-09^{* *}(1.07 \mathrm{e}-09)$ \\
\hline Manufacturing & $-0.00230(0.00171)$ & $-0.00110(0.00150)$ & $-0.00148(0.00142)$ & $-0.00252(0.00262)$ \\
\hline Industry & $0.00375 * * *(0.00111)$ & $0.00392 * * *(0.00119)$ & $0.00378 * * *(0.00117)$ & $0.00424 * * *(0.00151)$ \\
\hline Inflation & $-0.000992(0.00275)$ & $-0.000320(0.00298)$ & $0.00121(0.00325)$ & $-0.00410(0.00443)$ \\
\hline FDI & $0.00596(0.00375)$ & $0.00519(0.00358)$ & $0.00700 *(0.00388)$ & $0.00995(0.00675)$ \\
\hline PS & $-0.00315(0.0129)$ & $-0.0149(0.0166)$ & $0.0192(0.0143)$ & $0.00968(0.0179)$ \\
\hline RL & $-0.0296(0.0415)$ & $0.00582(0.0474)$ & $-0.0130(0.0419)$ & $-0.0284(0.0768)$ \\
\hline Ethnic & $-0.108 *(0.0612)$ & & & \\
\hline Language & & $-0.162 * * *(0.0610)$ & & \\
\hline Religion & & & $-0.267 * * *(0.0902)$ & \\
\hline Trust & & & & $0.150 *(0.0866)$ \\
\hline Constant & $0.962 * * *(0.0816)$ & $1.012 * * *(0.0762)$ & $1.024 * * *(0.0662)$ & $0.945 * * *(0.0972)$ \\
\hline Observations & 5805 & 5669 & 5773 & 3773 \\
\hline
\end{tabular}

Dependent variable: operational self-sufficiency (OSS). All estimations are based on using Huber-White heteroscedasticity-consistent standard errors. Standard errors in parentheses

$* * * p<0.01, * * p<0.05, * p<0.1$

qualitatively similar to the ones presented in Tables $4,5,6$, 7,8 , and $9 .^{17}$

We continue discussing the analysis using the individualism dimension as a measure of the extent to which structural social capital development is facilitated. As was mentioned above, the dataset we are able to apply for this variable is much smaller due to lack of data for a considerable number of countries in our dataset. ${ }^{18}$ Table 10 presents the results for the conditional mean regressions for the three dependent variables, i.e., Share of Female Borrowers (column 1), Average Loan per GNI per Capita (column 2), and Operational Self-Sufficiency (column 3). We also perform our estimations based on conditional median regression. The results emerging from these two sets of regressions are very similar. ${ }^{19}$ They clearly are supportive to the hypothesis that in individualistic societies the social performance of MFIs is generally better. Our measure of the individualism dimension is positively associated with the share of female borrowers and negative with the average loan size. With respect to financial performance, we do not find supportive evidence, however.

\footnotetext{
$\overline{17}$ The results of these analyses not reported in the paper but are available on request from the authors.

18 The number of observations for the regression models using individualism as our measure of the extent to which structural social capital development is facilitated varies between 2737 and 3207.

19 The results of these analyses not reported in the paper but are available on request from the authors.
}

Individualism is actually negatively associated with our measure of operational self-sufficiency, at least when we use the results for the conditional mean regression model. When we use the conditional median regression model, the coefficient for individualism remains negative, but it is no longer significant. In additional robustness tests (not reported), in which we run the same regressions as in Table 10, but with a larger set of control variables, we find very similar results.

As a final robustness test we redo all regressions presented in Tables 4, 5, 6, 7, 8, 9, and 10 (including the robustness tests for which we use conditional median regressions and a trimmed dataset), this time only using a sub-sample of the dataset. As was clear from the data description in Table 1, most information on MFIs is available for recent years, indicating that the dataset we have is unbalanced, especially for the earlier years. For this robustness test, we therefore only use data from 2006 to 2012 to see whether our results still hold when we have a less unbalanced dataset. The data for this period cover 70 $\%$ of the observations of the full dataset. The results of these analyses (not reported) are qualitatively similar to the ones presented in Tables $4,5,6,7,8,9$, and $10 .^{20}$

\footnotetext{
${ }^{20}$ We chose not to report the results of this robustness test as this would add another 48 tables to the already substantial number of tables we have. However, again, the results of these robustness analyses are available from the authors.
} 
Table 7 Fractionalization, generalized trust, and MFI social performance, extended model (conditional mean regressions)

\begin{tabular}{|c|c|c|c|c|}
\hline Variables & $\begin{array}{l}\text { (1) } \\
\text { ShareFemBorr }\end{array}$ & $\begin{array}{l}\text { (2) } \\
\text { ShareFemBorr }\end{array}$ & $\begin{array}{l}\text { (3) } \\
\text { ShareFemBorr }\end{array}$ & $\begin{array}{l}\text { (4) } \\
\text { ShareFemBorr }\end{array}$ \\
\hline MFI_AGE & $-0.00209 *(0.00122)$ & $-0.00184(0.00124)$ & $-0.00167(0.00122)$ & $-0.00375 * *(0.00158)$ \\
\hline MFI_AGEsq & $-9.20 \mathrm{e}-07(2.75 \mathrm{e}-05)$ & $5.31 \mathrm{e}-06(2.79 \mathrm{e}-05)$ & $-6.53 e-06(2.75 e-05)$ & $4.57 \mathrm{e}-05(3.49 \mathrm{e}-05)$ \\
\hline NoBorrLag_LN & $0.0274 * * *(0.00237)$ & $0.0276 * * *(0.00241)$ & $0.0271 * * *(0.00238)$ & $0.0261 * * *(0.00313)$ \\
\hline AssetsPerGLP_LagLN & $-0.0379 * * *(0.0121)$ & $-0.0495 * * *(0.0122)$ & $-0.0401 * * *(0.0120)$ & $-0.0509 * * *(0.0162)$ \\
\hline GrowthGDPcapitaPPP & $-0.000349(0.000421)$ & $0.000184(0.000421)$ & $7.63 \mathrm{e}-06(0.000417)$ & $0.000530(0.000616)$ \\
\hline GDPperCapitaPPP_Lag & $\begin{array}{c}-9.01 \mathrm{e}-05^{* * *} \\
(6.65 \mathrm{e}-06)\end{array}$ & $\begin{array}{c}-9.33 \mathrm{e}-05^{* * *} \\
\quad(6.89 \mathrm{e}-06)\end{array}$ & $\begin{array}{l}-8.92 \mathrm{e}-05^{* * *} \\
\quad(6.74 \mathrm{e}-06)\end{array}$ & $\begin{array}{c}-0.000122 * * * \\
(8.08 \mathrm{e}-06)\end{array}$ \\
\hline GDPperCapitaPPP_LagSq & $5.21 \mathrm{e}-09 * * *(4.16 \mathrm{e}-10)$ & $5.52 \mathrm{e}-09^{* * *}(4.28 \mathrm{e}-10)$ & $5.22 \mathrm{e}-09^{* * *}(4.20 \mathrm{e}-10)$ & $6.89 \mathrm{e}-09 * * *(4.93 \mathrm{e}-10)$ \\
\hline Manufacturing & $0.000695(0.000727)$ & $0.00186 * * *(0.000714)$ & $0.00209 * * *(0.000698)$ & $0.00380 * * *(0.000932)$ \\
\hline Industry & $0.00406 * * *(0.000884)$ & $0.00393 * * *(0.000903)$ & $0.00306 * * *(0.000894)$ & $0.00616^{* * *}(0.00119)$ \\
\hline Services & $0.00353 * * *(0.000728)$ & $0.00329 * * *(0.000764)$ & $0.00282 * * *(0.000755)$ & $0.00727 * * *(0.000944)$ \\
\hline Inflation & $-0.000393(0.000789)$ & $-0.000597(0.000854)$ & $0.000337(0.000855)$ & $0.000985(0.00106)$ \\
\hline FDI & $-0.00857 * * *(0.000910)$ & $-0.00836 * * *(0.000927)$ & $-0.00759 * * *(0.000914)$ & $-0.0113 * * *(0.00133)$ \\
\hline PS & $-0.0321 * * *(0.00708)$ & $-0.0248 * * *(0.00737)$ & $-0.0121 *(0.00704)$ & $-0.00620(0.00965)$ \\
\hline RL & $0.0788 * * *(0.0150)$ & $0.116^{* * *}(0.0147)$ & $0.129 * * *(0.0140)$ & $0.0531 * *(0.0212)$ \\
\hline $\mathrm{CC}$ & $0.0356 *(0.0192)$ & $-0.00549(0.0182)$ & $-0.0207(0.0175)$ & $0.0507 * *(0.0250)$ \\
\hline Ethnic & $-0.139 * * *(0.0209)$ & & & \\
\hline Language & & $-0.000750(0.0160)$ & & \\
\hline Religion & & & $-0.169 * * *(0.0222)$ & \\
\hline Trust & & & & $0.174 * * *(0.0608)$ \\
\hline Constant & $0.538 * * *(0.0574)$ & $0.470 * * *(0.0596)$ & $0.570 * * *(0.0580)$ & $0.258 * * *(0.0758)$ \\
\hline Observations & 4392 & 4286 & 4368 & 2788 \\
\hline$R^{2}$ & 0.212 & 0.206 & 0.212 & 0.256 \\
\hline
\end{tabular}

Dependent variable: Share of female borrowers. Standard errors in parentheses

$* * * p<0.01, * * p<0.05, * p<0.1$

Table 11 summarizes the results of the association between our variables of interest and financial and social performance of MFIs as shown in Tables 4, 5, 6, 7, 8, 9, and 10. In particular, the table shows the expected sign (discussed in "Hypotheses" section of this paper) as well as the actual sign we find after estimating the models. $\mathrm{A}+(-)$ indicates that we find a positive (negative) and significant coefficient. The general picture that emerges from this table is that we find support for most of our hypotheses regarding the association between our social dimensions and the social and financial performance of MFIs, the only exception being the association between individualism and MFIs' financial performance. ${ }^{21}$

Regarding endogeneity, we have taken the precautions that our particular dataset allowed us to take, as described in the previous section. While we cannot completely dismiss the possibility of unexplained individual-specific effects, we argue that reverse causality may not be a major

\footnotetext{
When we use data for the period 2006-2012 only, however, we do find weak evidence for a positive association between individualism and MFIs' financial performance.
}

issue. In particular, we believe it is far-fetched to assume that MFIs' social and financial performance would affect the considered social dimensions of their countries. While the values of these social dimensions may change over time, they change very slowly. Microfinance has developed starting with late 1970s and it has considerably scaled up relatively recently. It is therefore not very likely that microfinance has changed the values of these social dimensions for the countries they come from.

\section{Summary and Concluding Remarks}

As was indicated in the introduction, the market for microfinance has been booming, especially since the early 2000s. And although the global financial crisis led to a reduction of its growth, and notwithstanding the criticism it received especially from 2007 onwards, policy makers still see it as an important instrument to reduce poverty by policy makers. At the same time, the private sector has increasingly valued microfinance as an interesting SRI tool. This fits into the general recent trend of the increasing 
Table 8 Fractionalization, generalized trust, and MFI social performance, extended model (conditional mean regressions)

\begin{tabular}{|c|c|c|c|c|}
\hline Variables & $\begin{array}{l}\text { (1) } \\
\text { AvgLoanToGNIcapita }\end{array}$ & $\begin{array}{l}\text { (2) } \\
\text { AvgLoanToGNIcapita }\end{array}$ & $\begin{array}{l}\text { (3) } \\
\text { AvgLoanToGNIcapita }\end{array}$ & $\begin{array}{l}\text { (4) } \\
\text { AvgLoanToGNIcapita }\end{array}$ \\
\hline MFI_AGE & $0.00119(0.00739)$ & $-0.000156(0.00756)$ & $-0.00194(0.00744)$ & $-0.00392(0.00322)$ \\
\hline MFI_AGEsq & $0.000167(0.000163)$ & $0.000128(0.000167)$ & $0.000177(0.000165)$ & $0.000109(6.97 \mathrm{e}-05)$ \\
\hline NoBorrLag_LN & $-0.102 * * *(0.0142)$ & $-0.103 * * *(0.0146)$ & $-0.107 * * *(0.0144)$ & $-0.0363 * * *(0.00633)$ \\
\hline AssetsPerGLP_LagLN & $0.234 * * *(0.0716)$ & $0.266 * * *(0.0731)$ & $0.250 * * *(0.0723)$ & $0.0325(0.0325)$ \\
\hline GrowthGDPcapitaPPP & $0.00804 * * *(0.00256)$ & $0.00531 * *(0.00258)$ & $0.00503 * *(0.00256)$ & $0.00331 * * *(0.00125)$ \\
\hline GDPperCapitaPPP_Lag & $-1.27 \mathrm{e}-05(3.98 \mathrm{e}-05)$ & $1.28 \mathrm{e}-05(4.16 \mathrm{e}-05)$ & $-1.52 \mathrm{e}-05(4.07 \mathrm{e}-05)$ & $0.000117 * * *(1.65 \mathrm{e}-05)$ \\
\hline GDPperCapitaPPP_LagSq & $8.04 \mathrm{e}-10(2.52 \mathrm{e}-09)$ & $-8.41 \mathrm{e}-10(2.61 \mathrm{e}-09)$ & $5.63 \mathrm{e}-10(2.56 \mathrm{e}-09)$ & $-6.59 \mathrm{e}-09 * * *(1.02 \mathrm{e}-09)$ \\
\hline Manufacturing & $0.0106 * *(0.00428)$ & $0.00295(0.00423)$ & $0.00142(0.00414)$ & $0.00260(0.00186)$ \\
\hline Industry & $-0.0241 * * *(0.00531)$ & $-0.0219 * * *(0.00545)$ & $-0.0215 * * *(0.00541)$ & $-0.0316 * * *(0.00241)$ \\
\hline Services & $-0.0136 * * *(0.00422)$ & $-0.0129 * * *(0.00440)$ & $-0.0138 * * *(0.00437)$ & $-0.0225 * * *(0.00185)$ \\
\hline Inflation & $-0.00347(0.00482)$ & $-0.00230(0.00521)$ & $-0.00334(0.00522)$ & $-0.00403 *(0.00221)$ \\
\hline FDI & $0.0424 * * *(0.00562)$ & $0.0416 * * *(0.00575)$ & $0.0387 * * *(0.00569)$ & $0.0348 * * *(0.00277)$ \\
\hline PS & $0.241 * * *(0.0429)$ & $0.239 * * *(0.0451)$ & $0.150 * * *(0.0428)$ & $0.131 * * *(0.0198)$ \\
\hline RL & $-0.232 * *(0.0918)$ & $-0.587 * * *(0.0914)$ & $-0.498 * * *(0.0866)$ & $0.0234(0.0432)$ \\
\hline $\mathrm{CC}$ & $-0.363 * * *(0.116)$ & $0.00405(0.111)$ & $-0.00852(0.107)$ & $-0.328 * * *(0.0507)$ \\
\hline Ethnic & $0.908 * * *(0.126)$ & & & \\
\hline Language & & $0.409 * * *(0.0974)$ & & \\
\hline Religion & & & $0.343 * *(0.136)$ & \\
\hline Trust & & & & $-0.857 * * *(0.122)$ \\
\hline Constant & $1.951 * * *(0.345)$ & $2.231 * * *(0.356)$ & $2.460 * * *(0.348)$ & $2.562 * * *(0.153)$ \\
\hline Observations & 4883 & 4757 & 4851 & 3178 \\
\hline$R^{2}$ & 0.082 & 0.076 & 0.074 & 0.200 \\
\hline
\end{tabular}

Dependent variable: Average loan per GNI per capita. Standard errors in parentheses $* * * p<0.01, * * p<0.05, * p<0.1$

popularity of this type of investments (combining investors' financial objectives with concerns about environmental, social, and governance issues) around the world. Yet, in order to be able to secure sustained interest from private investors, it is important that MFIs can show evidence of their contribution to reducing poverty. It is, therefore, very important that we have a better understanding of the conditions that enable MFIs to contribute to poverty reduction in a financially sustainable way.

Previous research has investigated institution-specific factors, macroeconomic factors, and the formal institutional context as drivers of MFI financial and social performance. We add to this research by focusing on the relationship between the performance of MFIs and the extent to which social capital formation is facilitated in different countries. We render this as a potentially important driver of MFI performance, because the lending model many of these institutions still use extensively crucially depends on the availability and quality of social capital.

We use three types of social dimensions-i.e., fractionalization, generalized trust, and individualism-to proxy for the extent to which social capital formation is facilitated. In particular, a society's fractionalization indicates how easy/difficult is for individuals to develop cognitive social capital. Generalized trust indicates to what extent different societies are conducive of the development of relational social capital (i.e., how fast individuals can build respect, acceptance, friendship, sociability through social interactions). Individualist societies better facilitate the development of structural social capital (i.e., expanding social networks beyond the kin).

We use data from a sample of 100 countries to identify how country variations in terms of these social dimensions explain variation in the MFIs financial and social performance. Overall, our results indicate that MFIs perform better, in terms of both financial and social objectives, in societies where social capital can be developed more easily. Most importantly, we find that MFIs active in societies characterized by higher (linguistic, ethnic, and religious) fractionalization and hightrust societies show lower financial and social performance. These results are very stable over a large number of model specifications, data sub-samples, and estimation methods. Moreover, we find that in individualistic 
Table 9 Fractionalization, generalized trust, and MFI financial performance, extended model (conditional mean regressions)

\begin{tabular}{|c|c|c|c|c|}
\hline Variables & $\begin{array}{l}\text { (1) } \\
\text { OSS }\end{array}$ & $\begin{array}{l}\text { (2) } \\
\text { OSS }\end{array}$ & $\begin{array}{l}\text { (3) } \\
\text { OSS }\end{array}$ & $\begin{array}{l}\text { (4) } \\
\text { OSS }\end{array}$ \\
\hline MFI_AGE & $0.00887 * * *(0.00323)$ & $0.00848 * * *(0.00329)$ & $0.00868 * * *(0.00324)$ & $0.00685(0.00448)$ \\
\hline MFI_AGEsq & $-0.000158^{* *}(7.13 \mathrm{e}-05)$ & $-0.000148^{* *}(7.26 \mathrm{e}-05)$ & $-0.000158^{* *}(7.15 \mathrm{e}-05)$ & $-0.000110(9.65 \mathrm{e}-05)$ \\
\hline NoBorrLag_LN & $-0.00535(0.00624)$ & $-0.00653(0.00636)$ & $-0.00615(0.00627)$ & $0.000345(0.00881)$ \\
\hline AssetsPerGLP_LagLN & $-0.171 * * *(0.0322)$ & $-0.168 * * *(0.0328)$ & $-0.163 * * *(0.0324)$ & $-0.169 * * *(0.0466)$ \\
\hline GrowthGDPcapitaPPP & $0.00151(0.00112)$ & $0.00156(0.00112)$ & $0.00154(0.00111)$ & $-0.000698(0.00176)$ \\
\hline GDPperCapitaPPP_Lag & $-5.74 \mathrm{e}-06(1.75 \mathrm{e}-05)$ & $-1.24 \mathrm{e}-05(1.81 \mathrm{e}-05)$ & $-6.00 e-06(1.77 e-05)$ & $-9.32 \mathrm{e}-06(2.31 \mathrm{e}-05)$ \\
\hline GDPperCapitaPPP_LagSq & $-6.93 \mathrm{e}-10(1.11 \mathrm{e}-09)$ & $-4.85 \mathrm{e}-10(1.14 \mathrm{e}-09)$ & $-6.63 \mathrm{e}-10(1.12 \mathrm{e}-09)$ & $-9.40 \mathrm{e}-10(1.43 \mathrm{e}-09)$ \\
\hline Manufacturing & $-0.00124(0.00188)$ & $-0.000474(0.00185)$ & $-0.000838(0.00181)$ & $-0.000301(0.00260)$ \\
\hline Industry & $0.00633 * * *(0.00233)$ & $0.00553 * *(0.00238)$ & $0.00523 * *(0.00236)$ & $0.00960 * * *(0.00336)$ \\
\hline Services & $0.00299(0.00184)$ & $0.00229(0.00191)$ & $0.00208(0.00189)$ & $0.00595 * *(0.00256)$ \\
\hline Inflation & $0.000523(0.00221)$ & $0.000385(0.00225)$ & $0.00182(0.00225)$ & $-0.000420(0.00334)$ \\
\hline FDI & $0.00573 * *(0.00246)$ & $0.00489 *(0.00250)$ & $0.00686 * * *(0.00247)$ & $0.00940 * *(0.00385)$ \\
\hline PS & $-0.0130(0.0187)$ & $-0.0232(0.0196)$ & $0.00621(0.0186)$ & $0.00595(0.0275)$ \\
\hline RL & $-0.0553(0.0403)$ & $-0.0125(0.0398)$ & $-0.0173(0.0378)$ & $-0.0277(0.0601)$ \\
\hline $\mathrm{CC}$ & $0.0784(0.0515)$ & $0.0610(0.0486)$ & $0.0454(0.0469)$ & $0.0474(0.0712)$ \\
\hline Ethnic & $-0.0713(0.0554)$ & & & \\
\hline Language & & $-0.146 * * *(0.0424)$ & & \\
\hline Religion & & & $-0.251 * * *(0.0592)$ & \\
\hline Trust & & & & $0.109(0.170)$ \\
\hline Constant & $0.927 * * *(0.151)$ & $1.053 * * *(0.155)$ & $1.066 * * *(0.152)$ & $0.610 * * *(0.214)$ \\
\hline Observations & 4874 & 4752 & 4843 & 3171 \\
\hline$R^{2}$ & 0.018 & 0.020 & 0.021 & 0.017 \\
\hline
\end{tabular}

Dependent variable: operational self-sufficiency (OSS). Standard errors in parentheses $* * * p<0.01, * * p<0.05, * p<0.1$

Table 10 Individualism trust and MFI social and financial performance (conditional mean regressions)

\begin{tabular}{|c|c|c|c|}
\hline Variables & $\begin{array}{l}\text { (1) } \\
\text { ShareFemBorr }\end{array}$ & $\begin{array}{l}\text { (2) } \\
\text { AvgLoanToGNIcapita }\end{array}$ & $\begin{array}{l}\text { (3) } \\
\text { Operational Self-Sufficiency }\end{array}$ \\
\hline MFI_AGE & $0.00202(0.00141)$ & $-0.00239(0.00245)$ & $0.0107 * *(0.00429)$ \\
\hline MFI_AGEsq & $-8.35 \mathrm{e}-05^{* * *}(3.10 \mathrm{e}-05)$ & $0.000189^{* * *}(5.06 \mathrm{e}-05)$ & $-0.000221 * * *(7.91 \mathrm{e}-05)$ \\
\hline GrowthGDPcapitaPPP & $-0.000647(0.000788)$ & $0.00580 * * *(0.00169)$ & $0.000451(0.00131)$ \\
\hline GDPperCapitaPPP & $-9.73 \mathrm{e}-05^{* * *}(5.59 \mathrm{e}-06)$ & $1.00 \mathrm{e}-04 * * *(1.06 \mathrm{e}-05)$ & $-1.51 \mathrm{e}-05(2.54 \mathrm{e}-05)$ \\
\hline GDPperCapitaPPPsq & $5.08 \mathrm{e}-09 * * *(3.70 \mathrm{e}-10)$ & $-6.33 \mathrm{e}-09^{* * *}(6.54 \mathrm{e}-10)$ & $8.37 \mathrm{e}-11(1.47 \mathrm{e}-09)$ \\
\hline Manufacturing & $-0.00415 * * *(0.000995)$ & $0.00607 * * *(0.00201)$ & $-0.00517 * *(0.00204)$ \\
\hline Industry & $0.00437 * * *(0.00103)$ & $-0.00761 * * *(0.00209)$ & $0.00539 * * *(0.00178)$ \\
\hline Inflation & $-0.00286^{* * *}(0.000977)$ & $0.00569 * * *(0.00218)$ & $-0.00790 * *(0.00345)$ \\
\hline FDI & $-0.00570 * * *(0.00177)$ & $0.00850 *(0.00444)$ & $0.00685 * *(0.00275)$ \\
\hline PS & $0.00180(0.00869)$ & $0.108 * * *(0.0152)$ & $0.0462 *(0.0243)$ \\
\hline RL & $-0.0436 * * *(0.0160)$ & $0.146^{* *}(0.0661)$ & $-0.0819 * *(0.0341)$ \\
\hline $\operatorname{idv}$ & $0.00558 * * *(0.000561)$ & $-0.00757 * * *(0.00179)$ & $-9.65 \mathrm{e}-05(0.000988)$ \\
\hline Constant & $0.853 * * *(0.0433)$ & $0.388 * * *(0.110)$ & $1.125^{* * *}(0.198)$ \\
\hline Observations & 2737 & 3183 & 3207 \\
\hline$R^{2}$ & 0.295 & 0.146 & 0.019 \\
\hline
\end{tabular}

All estimations are based on using Huber-White heteroscedasticity-consistent standard errors. Standard errors in parentheses $* * * p<0.01, * * p<0.05, * p<0.1$ 
Table 11 Summary of the results using different social dimensions measures Source: This table shows the results from estimating the baseline model to which one of our social dimensions has been added (one by one). The table shows the expected sign (discussed in
"Methodology and Data" section of this paper) as well as the actual sign we find after estimating the models. $\mathrm{A}+(-)$ indicates that we find a positive (negative) and significant coefficient for a certain variable

\begin{tabular}{|c|c|c|c|c|c|c|}
\hline \multirow[t]{2}{*}{ Social dimensions } & \multicolumn{2}{|c|}{ Female borrowing } & \multicolumn{2}{|c|}{ Operational self-sufficiency } & \multicolumn{2}{|l|}{ Loan size } \\
\hline & Expected & Actual & Expected & Actual & Expected & Actual \\
\hline Fractionalization & - & - & - & - & + & + \\
\hline Trust & + & + & + & + & - & - \\
\hline Individualism & + & + & + & $0 /-$ & - & - \\
\hline
\end{tabular}

societies social performance of MFIs is higher, which is in line with our hypothesis. We do not find support for our hypothesis that financial performance of MFIs is higher in individualistic societies.

The results of this study have clear policy relevance. They suggest that the success of microfinance models depends on the extent to which the society is conducive to social capital development. In practical terms, this means that simply copying models such as group lending from one context to the other may lead to failure. In the past, MFIs have followed this strategy. The success of the Grameen Bank led to setting up similar microfinance initiatives around the world. Yet, the mechanism of the Grameen Bank model is rather specific. It may work well in the societal context of Bangladesh and other South Asian countries. This does not mean, however, that the model can be equally successful in the context of, for example, African countries.

This message may be important for MFIs when evaluating the performance of their operations and the type of financial services they provide. It may also be highly relevant for MFIs that are about to establish a (new) branch in a different region or country and have to consider which lending technology to use. The country context in which they (are about to) work may well determine the success of some types of lending technologies, while it may be barrier for the success of others.

Our study sheds light on the characteristics of the social contexts in which microfinance can be successful. This may contribute by raising awareness that microfinance is perhaps not the best solution to cater for the financial needs of all poor individuals around the world. This may call for other innovative solutions that are better suited for certain social contexts.

Future research may look into questions that focus on better understanding why established microfinance models work in one context, while they are failing in other contexts, by explicitly taking into account the difference in the societies' capacities to facilitate social capital formation.
Open Access This article is distributed under the terms of the Creative Commons Attribution 4.0 International License (http://crea tivecommons.org/licenses/by/4.0/), which permits unrestricted use, distribution, and reproduction in any medium, provided you give appropriate credit to the original author(s) and the source, provide a link to the Creative Commons license, and indicate if changes were made.

\section{References}

Aggarwal, R., Goodell, J. W., \& Selleck, L. J. (2015). Lending to women in microfinance: Role of social trust. International Business Review, 24(1), 55-65.

Ahlin, C., Lin, J., \& Maio, M. (2011). Where does microfinance flourish? Microfinance institution performance in macroeconomic context. Journal of Development Economics, 95(2), 105-120.

Ahlin, C., \& Townsend, R. (2007). Using repayment data to test across models of joint liability lending. Economic Journal, 117(517), F11-F51.

Alesina, A., Devleeschauwer, A., Easterly, W., Kurlat, S., \& Wacziarg, R. (2003). Fractionalization. Journal of Economic Growth, 8(2), 155-194.

Allik, J., \& Realo, A. (2004). Individualism-collectivism and social capital. Journal of Cross-Cultural Psychology, 35(1), 29-49.

Armendariz, B., \& Labie, M. (2011). Handbook of microfinance. Singapore: World Scientific.

Banerjee, A., Duflo, E., Glennerster, R., \& Kinnan, C. (2013). The miracle of microfinance? Evidence from a randomized evaluation, NBER Working Paper No. 18950. Cambridge: National Bureau of Economic Research

Battilana, J., \& Dorado, S. (2010). Building sustainable hybrid organizations: The case of commercial microfinance organizations. Academy of Management Journal, 53(6), 1419-1440.

Bauchet, J., Marshall, C., Starita, L., Thomas, J., \& Yalouris, A. (2011). Latest findings from randomized evaluations of microfinance, access to finance forum reports by CGAP and its partners, No. 2, December

Biswas, S. (2010). India's micro-finance suicide epidemic. $B B C$ News, Medak, Andhra Pradesh, updated 16 December 2010. Accessed May 18, 2016, from http://www.bbc.co.uk/news/ world-southasia-11997571.

Bjørnskov, C. (2006). Determinants of generalized trust: A crosscountry comparison. Public Choice, 130(1-2), 1-21.

Burzynska, K., \& Berggren, O. (2015). The impact of social beliefs on microfinance performance. Journal of International Development, 27(7), 1074-1097. 
Cassar, A., Crowley, L., \& Wydick, B. (2007). The effect of social capital on group loan repayment: Evidence from field experiments. Economic Journal, 117(517), F85-F106.

Collins, D., Morduch, J., Rutherford, S., \& Ruthven, O. (2009). Portfolios of the poor: How the world's poor live on $\$ 2$ a day. Princeton, NJ: Princeton University Press.

Dufhues, T., Buchenrieder, G., Euler, D. G., \& Munkung, N. (2011a). Network based social capital and individual loan repayment performance. Journal of Development Studies, 47(8), 1199-1215.

Dufhues, T., Buchenrieder, G., \& Munkung, N. (2013). Social capital and market imperfections: Accessing formal credit in Thailand. Oxford Development Studies, 41(1), 54-75.

Dufhues, T., Buchenrieder, G., \& Quoc, H. D. (2012). Social capital and loan repayment performance in Northern Vietnam. Agricultural Economics, 43(3), 277-292.

Dufhues, T., Buchenrieder, G., Quoc, H. D., \& Munkung, N. (2011b). Social capital and loan repayment performance in Southeast Asia. Journal of Socio-Economics, 40(5), 679-691.

El-Zoghbi, M., Gähwiler, B., \& Lauer, K. (2011). Cross-border funding of microfinance. CGAP Focus Note No. 70

Fukuyama, F. (1995). Trust: The social virtues and the creation of prosperity. New York: Free Press.

Hermes, N., Lensink, R., \& Mehrteab, H. T. (2005). Peer monitoring, social ties and moral hazard in group lending programs: Evidence from eritrea. World Development, 33(1), 149-169.

Hermes, N., \& Meesters, A. (2011). The performance of microfinance institutions: Do macro conditions matter. In B. Armendariz \& M. Labie (Eds.), The handbook of microfinance (pp. 173-201). Singapore: World Scientific.

Hofstede, G. (2001). Culture's consequences: Comparing values, behaviors, institutions, and organizations across nations (2nd ed.). Thousand Oaks, CA: Sage.

Hudon, M. (2011). Ethics in microfinance. In B. Armendariz \& M. Labie (Eds.), The handbook of microfinance (pp. 123-138). Singapore: World Scientific.

Hudon, M., \& Sandberg, J. (2013). The ethical crisis in microfinance: Issues, findings, and implications. Business Ethics Quarterly, 23(4), 561-589.

Inkeles, A. (2000). Measuring social capital and its consequences. Policy Sciences, 33(3/4), 245-268.

Juhasz, C. J. (2016). Behind the most successful microfinance IPO in India's history: What does gender lens investing have to do with it? Accessed May 31, 2016, from http://nextbillion.net/behindthe-most-successful-microfinance-ipo-in-indias-history-what-doe s-gender-lens-investing-have-to-do-with-it/.

Karlan, D. (2007). Social connections and group banking. Economic Journal, 117(517), F52-F84.

Knack, S., \& Keefer, P. (1997). Does social capital have and economic payoff? A cross-country investigation. Quarterly Journal of Economics, 112(4), 1251-1288.

Lewis, J. C. (2008). Microloan sharks. Stanford Social Innovation Review, 6(3), 54-59.

Mader, P. (2013). Rise and fall of microfi nance in India: The Andhra Pradesh crisis in perspective. Strategic Change, 22(1-2), 47-66.

Manos, R., \& Tsytrinbaum, L. (2014). Determinants of performance in the microfinance industry: The role of culture. In R. Mersland
\& Ø. Strøm (Eds.), Microfinance institutions: Financial and social performance (pp. 53-78). Palgrave McMillan: Basingstoke.

Masanjala, W. H. (2002). Can the Grameen Bank be replicated in Africa? Evidence from Malawi. Canadian Journal of Development Studies, 23(1), 87-103.

Mersland, R., D’Espallier, B., \& Supphellen, M. (2013). The effects of religion on development efforts: Evidence from the microfinance industry and a research agenda. World Development, 41(1), 145-156.

Mersland, R., Randøy, T., \& Ström, Ø. (2011). The impact of international influence on microbanks' performance: A global survey. International Business Review, 20(2), 163-176.

Money Control. (2016). Ujjivan IPO a top draw: Gets oversubscribed nearly 41 times. Accessed May 31, 2016, from http://www. moneycontrol.com/news/ipo-upcoming-issues/ujjivan-ipotop-dra w-gets-oversubscribed-nearly-41-times_6495321.html?utm_sour ce=ref_article

Morduch, J. (1999). The microfinance promise. Journal of Economic Literature, 37(4), 1569-1614.

Nahapiet, J., \& Ghoshal, S. (1998). Social capital, intellectual capital and the organizational advantage. Academy of Management Review, 23(2), 242-266.

Parsons, T., \& Shills, E. (1990). Values and social systems. In J. Alexander \& S. Seidman (Eds.), Culture and society: Contemporary debates (pp. 39-46). New York: Cambridge University Press.

Peña López, J. A., \& Sánchez Santos, J. M. (2014). Does corruption have social roots? The role of culture and social capital. Journal of Business Ethics, 122(4), 697-708.

Pohl, M., \& Tolhurst, N. (2010). Responsible business: How to manage a CSR Strategy Successfully. Chichester: Wiley.

Realo, A., \& Allik, J. (2009). On the relationship between social capital and individualism-collectivism. Social and Personality Psychology Compass, 3(6), 871-886.

Sundeen, L., \& Johnson, D. K. (2012). It's not what you know, it's who knows what you know: An econometric analysis of the effectiveness of microfinance in the presence of endogenous peer effects. Colorado College Working Paper 2012-2017

Vaessen, J., \& Bastiaensen, J. (1999). Social capital and institutions: In search of a conceptual framework for the analysis of local rural development. UFSIA Research Paper 036. http://anet. uantwerpen.be/docman/irua/3599cb/f03d20c7.pdf

Wagner, C., \& Winkler, A. (2013). The vulnerability of microfinance to financial turmoil: Evidence from the global financial crisis. World Development, 51, 71-90.

Walker, I. (2012). Is social capital fungible? The rise and fall of the Sanduk Microcredit Project in Ngazidja. Journal of Eastern African Studies, 6(4), 709-726.

Wydick, B., Karp Hayes, H., \& Hilliker Kempf, S. (2011). Social networks, neighborhood effects and credit access. World Development, 39(6), 974-982.

Wydick, W. B. (1999). Can social cohesion be harnessed to repair market failures? Evidence from group lending in Guatemala. Economic Journal, 109(457), 463-475. 